\title{
Long-term survival in lung transplant recipients depending on icu length of stay: outcome in a series of 653 consecutive patients
}

\author{
M Zemtsovski ${ }^{1 *}, M$ Østergaard ${ }^{1}$, P Bredahl', M Perch², C Møller ${ }^{3}$, M Iversen $^{2}$ \\ From ESICM LIVES 2015 \\ Berlin, Germany. 3-7 October 2015
}

\section{Introduction}

Over the last two decades lung transplantation (LT) has become the treatment of choice for various end-stage lung diseases. It is well-known that the majority of patients who underwent LT experienced complications postoperatively. Postoperative mortality has decreased due to improved surgical techniques and intensive care. However, very little is known about the long-term outcome of lung transplant recipients with prolonged intensive care length of stay (ICU LOS).

\section{Objectives}

To determine long-term survival after LT depending on ICU LOS.

\section{Methods}

A retrospective review of all patients receiving $\mathrm{LT}$ in Denmark in 1992-2014. The population of lung transplant recipients was divided into groups with respect to ICU LOS: 7, 14 and 28 days. Kaplan-Meier analysis was used to compare the overall survival between groups.

\section{Results}

Lung transplantation was performed in 653 patients. Single lung transplantation was performed in 330 cases, double lung transplantation in 323 cases. Main indications were chronic obstructive pulmonary disease $(\mathrm{n}=$ 272), alpha1-antitrypsin deficiency $(\mathrm{n}=141)$, cystic fibrosis $(\mathrm{n}=99)$, pulmonary fibrosis $(\mathrm{n}=67)$, sarcoidosis $(\mathrm{n}=29)$, primary pulmonary hypertension $(\mathrm{n}=14)$, and other end-stage lung diseases $(n=31)$.

${ }^{1}$ Copenhagen University Hospital - Rigshospitalet, Department of

Cardiothoracic Intensive Care, Copenhagen, Denmark

Full list of author information is available at the end of the article
The median ICU LOS was 3 days with interquartile range 5 and minimum-maximum 0-156 days. The median survival time (MST) for the entire series was 6.1 years.

Of the 637 patients who survived the first 7 days after LT, 155 (24\%) had ICU LOS more than 7 days. The MST in this group was 3.6 years compared with 7.4 years in the group of patients with ICU LOS $\leq 7$ days $(\mathrm{p}<0.001)$ (Figure 1$)$.

Of 631 patients who survived the first 14 days after LT, 85 (13\%) had ICU LOS more than 14 days. The MST in this group was 2.4 years compared with 7.4 years in the

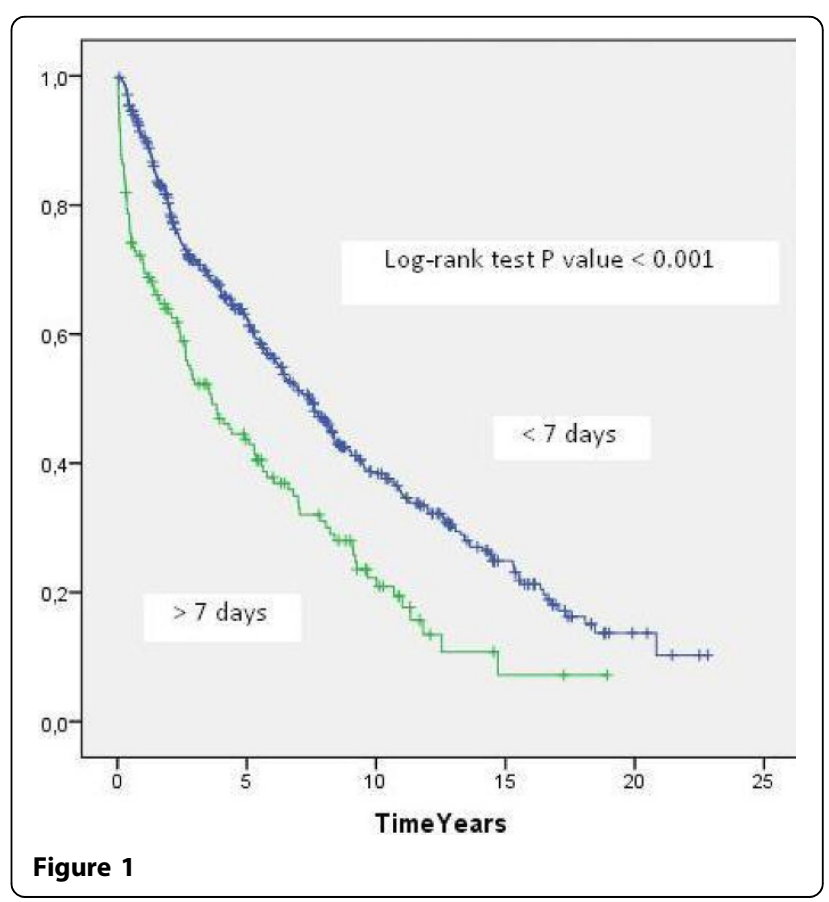

(c) 2015 Zemtsovski et al.; This is an Open Access article distributed under the terms of the Creative Commons Attribution License (http://creativecommons.org/licenses/by/4.0), which permits unrestricted use, distribution, and reproduction in any medium, provided the original work is properly cited. 

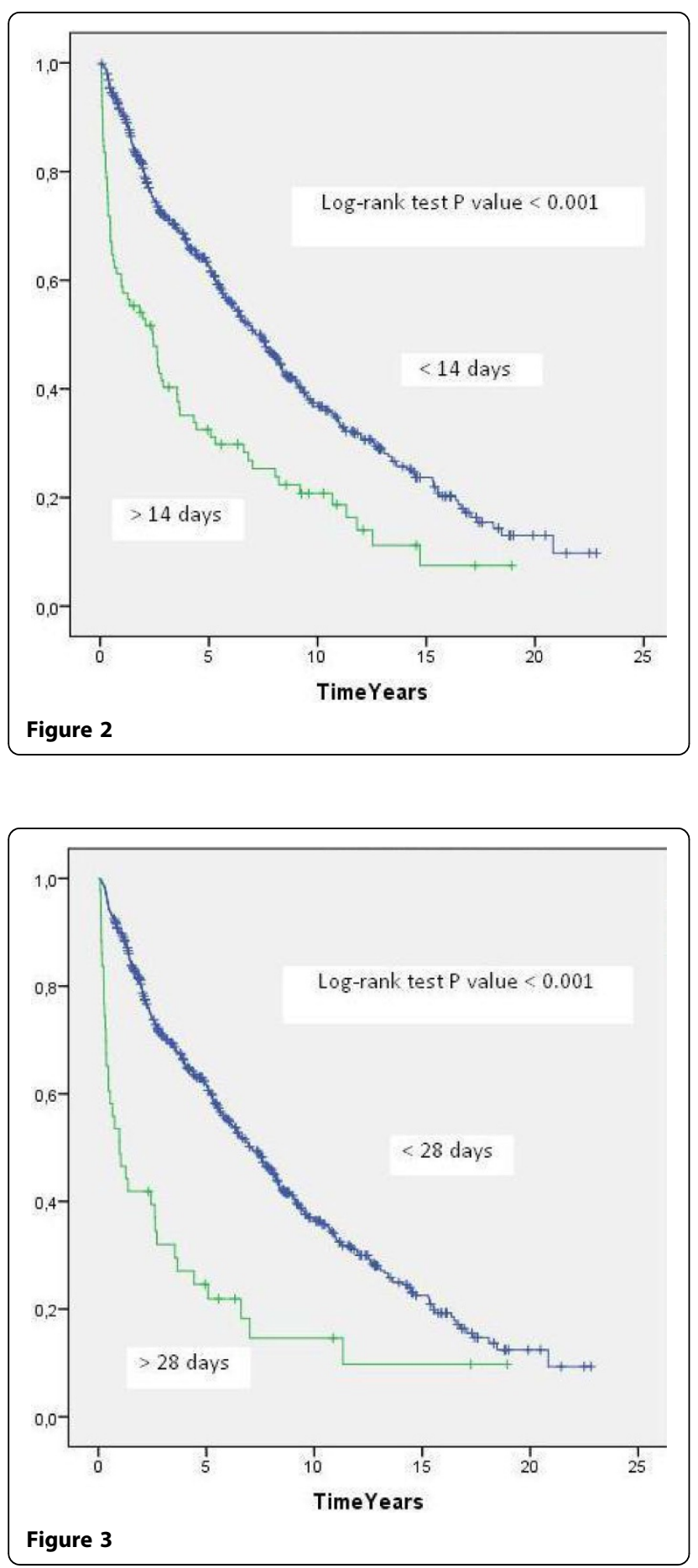

group of patients with ICU LOS $\leq 14$ days $(\mathrm{p}<0.001)$ (Figure 2).

Of 614 patients who survived the first 28 days after LT, 43 (7\%) had ICU LOS more than 28 days. The MST in this group was 1.0 year compared with 7.0 years in the group of patients with ICU LOS $\leq 28$ days $(\mathrm{p}<$ 0.001) (Figure 3).

\section{Conclusions}

A significant number of LT recipients required prolonged ICU LOS postoperatively. The prolonged ICU LOS was associated with poor long-term survival.

\section{Authors' details}

${ }^{1}$ Copenhagen University Hospital - Rigshospitalet, Department of Cardiothoracic Intensive Care, Copenhagen, Denmark. ${ }^{2}$ Copenhagen University Hospital - Rigshospitalet, Department of Cardiology, Division of Lung Transplantation, Copenhagen, Denmark. ${ }^{3}$ Copenhagen University Hospital - Rigshospitalet, Department of Cardiothoracic Surgery, Copenhagen, Denmark.

Published: 1 October 2015

doi:10.1186/2197-425X-3-S1-A450

Cite this article as: Zemtsovski et al:: Long-term survival in lung transplant recipients depending on icu length of stay: outcome in a series of 653 consecutive patients. Intensive Care Medicine Experimental 2015 3(Suppl 1):A450.

\section{Submit your manuscript to a SpringerOpen ${ }^{\circ}$ journal and benefit from:}

- Convenient online submission

- Rigorous peer review

- Immediate publication on acceptance

- Open access: articles freely available online

- High visibility within the field

- Retaining the copyright to your article

Submit your next manuscript at $>$ springeropen.com 